\title{
The Contribution of Alcohol Use, Other Lifestyle Factors and Working Conditions to Socioeconomic Differences in Sickness Absence
}

\author{
Jonas Landberg a,b Tomas Hemmingsson ${ }^{b, c}$ Lovisa Sydén ${ }^{d}$ Mats Ramstedt ${ }^{b}$ \\ ${ }^{a}$ Department of Public Health Sciences, Stockholm University, Stockholm, Sweden; ${ }^{b}$ Department of Clinical \\ Neuroscience, Karolinska Institutet, Stockholm, Sweden; ' Institute of Environmental Medicine, Karolinska Institutet, \\ Stockholm, Sweden; ${ }^{\mathrm{d}}$ Department of Public Health Sciences, Karolinska Institutet, Stockholm, Sweden
}

\section{Keywords}

Sickness absence $\cdot$ Socioeconomic differences · Alcohol use $\cdot$ Lifestyle factors · Working conditions

\begin{abstract}
Introduction: This study investigates how alcohol use contributes to the social gradient in sickness absence. Other factors assessed include lifestyle factors (smoking, physical activity and body mass index), physical and psychosocial working conditions. Methods: The study used baseline data from the Stockholm public health cohort 2006, with an analytical sample of 17,008 respondents aged 25-64 years. Outcome variables included self-reported short-term (<14 days) and register-based long-term (>14 days) sickness absence. Socioeconomic position (SEP) was measured by occupational class. Alcohol use was measured by average weekly volume and frequency of heavy episodic drinking. Negative binominal regression was used to estimate sex-specific SEP differences in sickness absence, before and after adjusting for alcohol use and the additional explanatory factors. Results: Adjusting for alcohol use attenuated the SEP differences in long-term sickness absence by $20 \%$ for men and $14 \%$ for women. Alcohol use explained a smaller proportion of the differences in shortterm sickness absence. Alcohol use in combination with other lifestyle factors attenuated the SEP differences (20-35\%) for
\end{abstract}

both outcomes. Physical working conditions explained more than half of the gradient in long-term sickness absence, whereas psychosocial conditions had greater impact on short-term sickness absence among men. Discussion/Conclusion: Alcohol use explains a substantial proportion of the SEP disparities in long-term sickness absence among men. The effect is smaller among women and for short-term sickness absence. Our findings support the notion that physical working conditions constitute the key explanatory variable for SEP differences in long-term sickness absence, but add that psychosocial working conditions have greater impact on the gradient in short-term sickness absence among men.

(c) 2019 The Author(s)

Published by S. Karger AG, Basel

\section{Introduction}

Sickness absence causes significant costs for the individual and society and is an important indicator of working ability and health among employees [1-3]. There is also evidence that sickness absence predicts other adverse outcomes, including disability pension and mortality [4-6]. In line with most other major health outcomes, the distribution of sickness absence tends to be socially patterned, with higher rates among groups with lower socioeconomic position (SEP) [7-10]. The

\begin{tabular}{ll}
\hline KARGER & $\begin{array}{l}\text { (c) } 2019 \text { The Author(s) } \\
\text { Published by S. Karger AG, Basel }\end{array}$ \\
E-Mail karger@karger.com & $\begin{array}{l}\text { This article is licensed under the Creative Commons Attribution- } \\
\text { NonCommercial-NoDerivatives 4.0 International License (CC BY- } \\
\text { NC-ND) (http://www.karger.com/Services/OpenAccessLicense). } \\
\text { Usage and distribution for commercial purposes as well as any dis- } \\
\text { tribution of modified material requires written permission. }\end{array}$
\end{tabular}


mechanisms and pathways underlying this social gradient in sickness absence have not been fully identified in the research literature [7]. However, recent research indicates that a substantial proportion of the gradient may be explained by a host of factors that are both more prevalent in groups with lower SEP, and increase the risk of sickness absence. Physical working conditions appear to be the strongest explanatory factor in this context, but psychosocial working conditions and lifestyle behaviours have also been found to contribute significantly to the gradient [8-12].

Alcohol use is one factor that, despite its plausible importance in this context, has received less attention. It is well established that alcohol consumption is related to a wide range of chronic and acute health outcomes, including sickness absence [13-20]. Single bouts of heavy episodic drinking (HED) occasions that result in intoxication and subsequent hangover may impair work capacity and increase the risk for short-term sickness absence. Acute intoxication is also related to an increased risk for accidents and injuries, which account for a significant part of all sickness absence [21]. Moreover, chronic heavy drinking increases the risk for many somatic and psychiatric diseases; the latter comprise one of the main groups of diagnoses behind sickness absence [2]. In line with this, the economic burden of alcohol-related work absence has been found to be substantial. At the global level, the yearly cost of alcohol-related work absence has been estimated to be 30-65 billion dollars, corresponding to $>10 \%$ of the total global cost of alcohol [16, 22].

Considering that alcohol-related health outcomes also tend to show a social gradient that is steeper than for other outcomes, for example, total mortality [23-25], it would be reasonable to hypothesize that a significant proportion of the socioeconomic differences in sickness absence may be explained by an unequal exposure to harmful alcohol use across socioeconomic groups.

However, previous studies of the link between SEP and sickness absence tend to include alcohol use in an aggregated measure of lifestyle behaviours rather than as a single explanatory variable $[8,11,12]$, thus hampering assessments of the specific contribution of alcohol in this context. Moreover, most studies have considered only one dimension of alcohol consumption, that is, average volume $[9,11,12]$, possibly missing out on the risks of different alcohol use patterns. Within alcohol epidemiology, it is well established that both volume of consumption and pattern of drinking (e.g., frequency of HED) should be considered when assessing the link between alcohol use and health outcomes [15]. In fact, recent re- search suggests that HED, rather than volume of consumption, contributes to the socioeconomic differences in health outcomes such as alcohol-related morbidity and total mortality $[26,27]$.

The present study aims to overcome the limitations of earlier research on the contribution of alcohol use to the social gradient in sickness absence. To this end, we will estimate the specific contribution of alcohol use (including measures of both levels and patterns of drinking) to the socioeconomic differences (measured by occupational class) in sickness absence, using a large representative public health cohort from Stockholm County. Building on previous research, we also assess the contribution of other factors, including lifestyle factors (smoking, physical activity, and body mass index [BMI]), and physical and psychosocial working conditions. To further strengthen our approach, we include 2 outcome measures that may have a differential association with alcohol use and the other explanatory variables: self-reported short-term $(<14$ days) sickness absence and long-term, register-linked sickness absence (measured after day 14). Seeing that the SEP differences in alcohol-related harm tend to be larger for more severe consequences, such as alcohol-related morbidity, a plausible hypothesis in this context would be that alcohol accounts for a more substantial proportion of the social gradient in long-term than in short-term sickness absence.

\section{Material and Methods}

\section{Study Population}

The analyses were based on data from the 2006 baseline of the Stockholm Public Health Cohort (SPHC). SPHC is a cohort study with data from an area- and sex-stratified random sample of residents in Stockholm County, Sweden. SPHC data collection procedures and response rates are described in full elsewhere [28]. The SPHC survey is sent out every fourth year and comprises questions on health, lifestyle, social relations, housing, finances, occupation, work environment and sickness absence. To mitigate sampling error and attrition bias, the SPHC employed calibrated weights computed by Statistics Sweden using registerbased auxiliary data on age, sex, country of birth, area of residence, marital status, income and educational level, along with their covariation with survey-based data [28]. Out of the sample frame in 2006 (56,634 individuals aged 18-84), 34,707 individuals (61\%) responded. Respondents who were between 25 and 64 years of age, employed or engaged in similar activity daily and who had responded to questions about all the variables studied, constituted the analytical sample for the present study $(n=$ 17,008). Respondents younger than 25 years at baseline were excluded to allow more established SEP. In the analyses of longterm sickness absence, we also excluded respondents with register-based (>14 days) sickness absence in the year before baseline, resulting in a study sample of $n=15,983$. 


\section{Measures}

Outcome

The study included 2 outcome measures. Data on short-term sickness absence was obtained by self-reported information and measured at baseline by the question "Have you been on sick leave in shorter spells ( $<14$ days in a row) the last 12 months?", with 5 response options: no, 1, 2-4, 5-9 and 10 times or more. We coded these options into $0,1,3,7$ and 10 and used the variable as a count outcome in the analyses. Information on longterm sickness absence was obtained by record linkage to the Swedish social insurance registers, compiled by the Swedish Social Insurance Agency (Försäkringskassan). In the Swedish insurance system, the first 14 days of a sickness absence spell (minus the first "qualifying" day) is covered by the employer. From day 14 onwards, the sickness benefits are paid out by the Social Insurance Agency and registered in the social insurance registers. Consequently, the register includes number of sickness absence days, after day 14 . As outcome for long-term sickness absence, we counted the number of sickness absence days (after day 14) that occurred between entry into the study (14 September 2006 at earliest) until date of emigration, retirement by age, disability pension, death or end of follow-up (December $31,2008)$.

\section{Exposure: SEP}

In line with previous studies, SEP was measured by occupational class [8-10]. The information was retrieved from the baseline survey where the respondents indicated their current (or previous) occupation, which was categorized into 6 groups according to the Swedish socioeconomic classification of occupations [29]: unskilled workers, skilled workers, lower non-manual employees, intermediate non-manual employees, higher non-manual employees and self-employed. The 2 lowest SEP groups, unskilled and skilled workers, displayed similar associations with both the outcome and explanatory variables and were therefore collapsed into 1 group: manual workers.

\section{Explanatory Variables}

Alcohol use was measured in 2 ways. One was the average volume of weekly alcohol consumption (in grams 100\% alcohol/week) during the last 12 months, categorized into 4 groups with different cut-offs for men and women [30]: abstainers ( $0 \mathrm{~g})$, light ( 1 up to $84 \mathrm{~g})$, moderate (84-252 $\mathrm{g}$ for men, 84-168 $\mathrm{g}$ for women) and heavy drinkers ( $>252 \mathrm{~g}$ for men, $>168 \mathrm{~g}$ for women). The other was the frequency of $H E D$, defined as the number of occasions when the amount of alcohol consumed corresponded to at least $120 \mathrm{~g}$ $100 \%$ alcohol during the previous 12 months, divided into 5 groups: abstainers, drinkers with no HED, HED 1-6 times per year, HED 1- 3 times a month, HED once a week or more often. It should be noted that the threshold for HED is high, by European standards. Still, it has been shown to contribute to socioeconomic differences in alcohol-related morbidity and total mortality in 2 previous studies [26, 27].

Other lifestyle factors included smoking, physical activity and BMI. Smoking was categorized into non-smoker (never smoked daily), current daily smoker, and former daily smoker (during at least 6 months). Physical activity was based on reported workouts in leisure time during a normal week the previous year, and categorized into 3 groups: inactive, moderately active, and frequently active. $B M I$ was categorized by established cut-points; underweight
$(<18.49)$, average weight (18.5-24.99), overweight (25-29.99) and obese $(>30)$.

Working conditions: Physical working conditions were assessed by a question measuring the physical workload [10]: "How much have you moved or exerted yourself physically at work during the past 12 months?" with the response alternatives: sedentary work (your job is predominantly sedentary); light physical work (your work involves moving/walking around a lot, but no heavy lifts); moderately heavy work (your work involves moving/walking around a lot, some heavy lifts, and/or walking on stairs or slopes); and heavy work (your work involves lifting heavy objects and exerting a lot of physical effort). The responses were coded into a variable with the categories: sedentary work, light work, moderately heavy work and heavy work.

Psychosocial working conditions were assessed by 8 questions measuring the degree of job control and job demands. The questions were derived from the demand-control model that builds on the notion that employees who do not have sufficient job control to meet the demands of their job will experience job strain, which in turn is related to increased risk of several health outcomes, including sickness absence $[31,32]$. The questions were combined into a variable with the categories: high strain (low control with high demands); passive work (low control with low demands); active work (high control with high demands); and low strain (high control with low demands).

Initial analyses revealed significant interaction between sex and SEP in relation to both short-term and long-term sickness absence. Therefore, we stratified the main analyses by sex. All models were adjusted for the background covariates age (as a continuous variable) and country of birth, coded into 5 groups: Sweden, Scandinavia (except Sweden), Europe (except Scandinavia), Middle East and North Africa, and all other countries.

\section{Statistical Analyses}

In line with previous studies, we used generalized linear model regression to estimate SEP differences in the risk for sickness absence $[8,9]$. Since the distribution of both outcomes was overdispersed, we applied Negative binomial regression (rather than Poisson regression). The regression estimates express rate ratios (RR), and their 95\% CI. For long-term sickness absence, we included an offset variable measuring the logarithm of person-time at risk in the study, calculated from the date a participant entered the study (September 14, 2006 at earliest) until being censored by date of emigration, retirement by age, disability pension, death or end of follow-up (December 31, 2008). The Statistics Sweden calibration weights mentioned above under "Study population" were used to ensure that the study sample was representative of the target population of Stockholm County in terms of the major sociodemographic and health-related determinants [28].

In a first step, we estimated the individual association with short-term and long-term sickness absence for each of the explanatory variables (adjusted for age and country of birth). Next, we estimated crude models including SEP (adjusted for age and country of birth), followed by a series of models with separate adjustment for alcohol use, alcohol use + lifestyle factors, physical and psychosocial working conditions. Finally, we estimated a fully adjusted model where all explanatory variables were entered concurrently. Each model displays the RR of sickness absence among the 
Table 1. Prevalence (\%) of alcohol use, other lifestyle behaviours and physical and psychosocial working conditions by SEP group, men

\begin{tabular}{|c|c|c|c|c|c|c|}
\hline & MW & LNME & INME & SE & HNME & Total \\
\hline \multicolumn{7}{|l|}{ Volume of consumption } \\
\hline Abstainers & 12 & 6 & 4 & 8 & 4 & 7 \\
\hline Light drinkers & 38 & 35 & 38 & 32 & 36 & 37 \\
\hline Moderate drinkers (ref.) & 35 & 44 & 45 & 46 & 49 & 44 \\
\hline Heavy drinkers & 14 & 16 & 12 & 14 & 10 & 13 \\
\hline \multicolumn{7}{|l|}{ HED } \\
\hline Abstainers & 12 & 6 & 4 & 8 & 4 & 7 \\
\hline Drinkers with no HED & 22 & 25 & 30 & 31 & 38 & 30 \\
\hline HED 1-6 times/year (ref.) & 32 & 37 & 38 & 31 & 36 & 35 \\
\hline HED $\leq 3$ times/month & 21 & 21 & 21 & 22 & 18 & 20 \\
\hline HED > once a week & 12 & 11 & 6 & 8 & 4 & 8 \\
\hline \multicolumn{7}{|l|}{ Smoker } \\
\hline Never daily smoker (ref.) & 53 & 63 & 66 & 55 & 71 & 62 \\
\hline Former daily smoker & 26 & 26 & 26 & 31 & 24 & 26 \\
\hline Daily smoker & 21 & 11 & 8 & 14 & 5 & 12 \\
\hline \multicolumn{7}{|l|}{ BMI } \\
\hline Underweight, $<18.49$ & 0.4 & 0.5 & 0.3 & 0.1 & 0.3 & 0.3 \\
\hline Normal, 18.5-24.99 (ref.) & 44 & 46 & 49 & 45 & 56 & 49 \\
\hline Overweight, 25-29.99 & 42 & 43 & 41 & 46 & 38 & 41 \\
\hline Obese, $>30$ & 13 & 11 & 10 & 9 & 6 & 10 \\
\hline \multicolumn{7}{|l|}{ Physical activity in leisure time } \\
\hline Frequently active (ref.) & 37 & 49 & 55 & 44 & 59 & 49 \\
\hline Moderately active & 46 & 39 & 36 & 44 & 34 & 39 \\
\hline Inactive & 18 & 12 & 9 & 12 & 7 & 11 \\
\hline \multicolumn{7}{|l|}{ Physical working cond. } \\
\hline Sedentary (ref.) & 11 & 45 & 53 & 31 & 73 & 44 \\
\hline Light & 21 & 33 & 32 & 27 & 24 & 26 \\
\hline Moderate & 39 & 18 & 13 & 24 & 3 & 19 \\
\hline Heavy & 29 & 03 & 02 & 18 & 0 & 11 \\
\hline \multicolumn{7}{|l|}{ Psychosocial working conditions } \\
\hline Low strain (ref.) & 22 & 30 & 25 & 35 & 27 & 27 \\
\hline Active & 29 & 44 & 55 & 51 & 62 & 49 \\
\hline Passive & 18 & 9 & 6 & 6 & 3 & 8 \\
\hline High strain & 31 & 17 & 14 & 8 & 8 & 16 \\
\hline
\end{tabular}

All $p$ values for trend across SEP categories $<0.001\left(\chi^{2}\right)$.

MW, manual workers; LNME, lower non-manual employees; INME, intermediate non-manual employees; SE, self-employed; HNME, higher non-manual employees; HED, heavy episodic drinking; BMI, body mass index; SEP, socioeconomic position.

most disadvantaged (manual workers) compared to the most advantaged SEP group (higher non-manual employees).

The contribution of the explanatory variables on the SEP differences in sickness absence was estimated by calculating the percentage reduction in the RRs, after adjustment of the explanatory variables at issue, using the following formula:

$$
\left(\mathrm{RR}_{\text {unadjusted }}-\mathrm{RR}_{\text {adjusted }}\right) /\left(\mathrm{RR}_{\text {unadjusted }}-1\right) \times 100
$$

In addition, we conducted sensitivity analyses with (i) the crude models adjusted for each alcohol use variable separately, (ii) models including having $>100$ days of long-term sickness absence during follow-up as outcome, and (iii) the crude models adjusted for alcohol use after exclusion of abstainers. The results of these analyses are not reported in tables but are commented and discussed in the text.

\section{Results}

Tables 1 and 2 show the distribution of alcohol use, other lifestyle factors and working conditions across the SEP groups. The prevalence of the variables generally shows a marked social gradient for both sexes. Compared 
Table 2. Prevalence (\%) of alcohol use, other lifestyle behaviours and physical and psychosocial working conditions by SEP group, women

\begin{tabular}{|c|c|c|c|c|c|c|}
\hline & MW & LNME & INME & SE & HNME & Total \\
\hline \multicolumn{7}{|l|}{ Volume of consumption } \\
\hline Abstainers & 20 & 9 & 8 & 12 & 4 & 10 \\
\hline Light drinkers & 54 & 56 & 58 & 50 & 56 & 56 \\
\hline Moderate drinkers (ref.) & 20 & 27 & 27 & 26 & 30 & 26 \\
\hline Heavy drinkers & 6 & 9 & 8 & 11 & 9 & 8 \\
\hline \multicolumn{7}{|l|}{ HED } \\
\hline Abstainers & 20 & 9 & 8 & 12 & 4 & 10 \\
\hline Drinkers with no HED & 46 & 58 & 65 & 62 & 73 & 61 \\
\hline HED 1-6 times/year (ref.) & 20 & 23 & 19 & 16 & 17 & 19 \\
\hline HED $\leq 3$ times/month & 10 & 8 & 5 & 6 & 4 & 7 \\
\hline HED > once a week & 3 & 2 & 2 & 2 & 1 & 2 \\
\hline \multicolumn{7}{|l|}{ Smoker } \\
\hline Never daily smoker (ref.) & 46 & 50 & 60 & 54 & 64 & 55 \\
\hline Former daily smoker & 29 & 33 & 29 & 30 & 28 & 30 \\
\hline Daily smoker & 26 & 17 & 11 & 16 & 7 & 15 \\
\hline \multicolumn{7}{|l|}{ BMI } \\
\hline Underweight, $<18.49$ & 2 & 2 & 2 & 3 & 3 & 2 \\
\hline Normal, 18.5-24.99 (ref.) & 60 & 64 & 69 & 71 & 75 & 68 \\
\hline Overweight, 25-29.99 & 28 & 23 & 22 & 19 & 18 & 22 \\
\hline Obese, $>30$ & 10 & 10 & 6 & 7 & 5 & 8 \\
\hline \multicolumn{7}{|l|}{ Physical activity in leisure time } \\
\hline Frequently active (ref) & 35 & 45 & 50 & 49 & 55 & 47 \\
\hline Moderately active & 51 & 44 & 42 & 44 & 39 & 44 \\
\hline Inactive & 14 & 11 & 8 & 7 & 6 & 9 \\
\hline \multicolumn{7}{|l|}{ Physical working cond. } \\
\hline Sedentary (ref.) & 6 & 63 & 41 & 35 & 69 & 44 \\
\hline Light & 27 & 25 & 38 & 35 & 27 & 30 \\
\hline Moderate & 46 & 11 & 19 & 23 & 3 & 20 \\
\hline Heavy & 21 & 1 & 2 & 7 & 0.5 & 6 \\
\hline \multicolumn{7}{|l|}{ Psychosocial working conditions } \\
\hline Low strain (ref.) & 23 & 30 & 24 & 46 & 23 & 27 \\
\hline Active & 31 & 33 & 51 & 45 & 60 & 45 \\
\hline Passive & 15 & 15 & 7 & 4 & 4 & 9 \\
\hline High strain & 32 & 23 & 18 & 5 & 13 & 19 \\
\hline
\end{tabular}

All $p$ values for trend across SEP categories $<0.001\left(\chi^{2}\right)$.

MW, manual workers; LNME, lower non-manual employees; INME, intermediate non-manual employees; SE, self-employed; HNME, higher non-manual employees; HED, heavy episodic drinking; BMI, body mass index; SEP, socioeconomic position.

to the least disadvantaged SEP group (higher non-manual employees), respondents in the most disadvantaged SEP group (manual workers) were more likely to be heavy drinkers, to HED once a week or more often, smoke daily be obese and be sedentary in leisure time. With regard to working conditions, manual workers more often reported heavy working conditions and high work strain. Exceptions to the gradient included heavy drinking among women, where the prevalence was somewhat lower among manual workers (6\%) than among higher-non manual employees (9\%). Moreover, for both sexes, the proportion of abstainers was highest among manual workers.
The Association with Sickness Absence for Each of the Explanatory Variables

Tables 3 and 4 show the individual association between each explanatory factors and short-term and longterm sickness absence, adjusted for age and country of birth and stratified by sex.

Volume of consumption was significantly associated with both short-term and long-term sickness absence among men and women. The associations generally revealed U-shaped risk functions, with elevated rates of sickness absence among abstainers and heavy drinkers relative to moderate drinkers. For instance, heavy drinkers had between 50 and $70 \%$ higher rates of long-term 
Table 3. Rate ratios of number of self-reported short sickness absence spells ( $<14$ days) by alcohol use, other lifestyle behaviours, and working conditions. All models, adjusted for age and country of birth

\begin{tabular}{|c|c|c|c|c|}
\hline & \multicolumn{2}{|l|}{ Men } & \multicolumn{2}{|c|}{ Women } \\
\hline & $\mathrm{RR}$ & $95 \% \mathrm{CI}$ & $\mathrm{RR}$ & $95 \% \mathrm{CI}$ \\
\hline \multicolumn{5}{|l|}{ Volume of consumption } \\
\hline Abstainers & 1.20 & $0.97-1.49$ & 1.35 & $1.16-1.57$ \\
\hline Light drinkers & 1.12 & $1.01-1.24$ & 1.09 & $1.00-1.19$ \\
\hline Moderate drinkers (ref.) & 1.00 & & 1.00 & \\
\hline Heavy drinkers & 1.22 & $1.06-1.40$ & 1.21 & $1.06-1.38$ \\
\hline \multicolumn{5}{|l|}{ HED } \\
\hline Abstainers & 1.17 & $0.94-1.47$ & 1.28 & $1.11-1.48$ \\
\hline Drinkers with no HED (ref.) & 1.00 & & 1.00 & \\
\hline HED 1-6 times/year & 1.07 & $0.95-1.20$ & 1.05 & $0.96-1.15$ \\
\hline HED $\leq 3$ times/month & 1.03 & $0.89-1.19$ & 1.00 & $0.86-1.16$ \\
\hline HED > once a week & 1.33 & $1.11-1.59$ & 1.49 & $1.18-1.88$ \\
\hline \multicolumn{5}{|l|}{ Daily smoking } \\
\hline Never daily smoker (ref.) & 1.00 & & 1.00 & \\
\hline Former daily smoker & 1.03 & $0.92-1.15$ & 1.05 & $0.96-1.14$ \\
\hline Daily smoker & 1.28 & $1.10-1.49$ & 1.23 & $1.11-1.36$ \\
\hline \multicolumn{5}{|l|}{ BMI } \\
\hline Underweight, $<18.49$ & 1.10 & $0.60-2.03$ & 0.78 & $0.59-1.02$ \\
\hline Normal, 18.5-24.99 (ref.) & 1.00 & & 1.00 & \\
\hline Overweight, 25-29.99 & 1.03 & $0.93-1.14$ & 1.35 & $1.24-1.47$ \\
\hline Obese, $>30$ & 1.28 & $1.12-1.47$ & 1.55 & $1.36-1.76$ \\
\hline \multicolumn{5}{|l|}{ Physical activity in leisure time } \\
\hline Frequently active (ref.) & 1.00 & & 1.00 & \\
\hline Moderately active & 1.23 & $1.11-1.35$ & 1.21 & $1.12-1.30$ \\
\hline Inactive & 1.66 & $1.45-1.91$ & 1.52 & $1.33-1.75$ \\
\hline \multicolumn{5}{|l|}{ Physical working conditions } \\
\hline Sedentary (ref.) & 1.00 & & 1.00 & \\
\hline Light & 0.94 & $0.84-1.05$ & 1.03 & $0.95-1.13$ \\
\hline Moderate & 1.16 & $1.03-1.30$ & 1.19 & $1.09-1.31$ \\
\hline Heavy & 1.41 & $1.20-1.64$ & 1.43 & $1.23-1.66$ \\
\hline \multicolumn{5}{|l|}{ Psychosocial working conditions } \\
\hline Low strain (ref.) & 1.00 & & 1.00 & \\
\hline Active & 1.17 & $1.04-1.32$ & 1.24 & $1.13-1.37$ \\
\hline Passive & 1.45 & $1.21-1.72$ & 1.18 & $1.01-1.38$ \\
\hline High strain & 2.15 & $1.87-2.47$ & 1.58 & $1.42-1.75$ \\
\hline
\end{tabular}

HED, heavy episodic drinking; BMI, body mass index.

sickness absence among women (RR 1.54, 95\% CI [1.01$2.36])$ and men (1.69 [1.05-2.74]). The corresponding estimates for abstainers were somewhat larger, with a $>2$ fold increase in rates of long-term sickness absence for both sexes.

Frequency of HED was significantly related to risk of short-term sickness absence among both sexes. Respondents with HED once a week or more often, had between 30 and $50 \%$ higher rates of short-term sickness absence compared to drinkers with no HED. However, for longterm sickness absence, we only found a significant association among men. Here HED once a week or more often was associated with a twofold $(2.14[1.27-3,58])$ increase in rates of long-term sickness absence relative to drinkers with no HED.

For all remaining lifestyle and working condition variables, individuals belonging to the most disfavoured category evidenced considerably higher levels of both self-reported and register-based sickness absence. Still, some differences between the 2 outcomes were revealed. For instance, being a current daily smoker, having an inactive leisure time (in men) or physically heavy work was more strongly associated with long-term than shortterm sickness absence for both sexes. 
Table 4. Rate ratios of number of long-term sickness absence days ( $>14$ days) by alcohol use, other lifestyle behaviours and working conditions. All models, adjusted for age and country of birth

\begin{tabular}{|c|c|c|c|c|}
\hline & \multicolumn{2}{|l|}{ Men } & \multicolumn{2}{|c|}{ Women } \\
\hline & $\mathrm{RR}$ & $95 \%$ CI & $\mathrm{RR}$ & $95 \% \mathrm{CI}$ \\
\hline \multicolumn{5}{|l|}{ Volume of consumption } \\
\hline Abstainers & 2.18 & $1.15-4.13$ & 2.46 & $1.74-3.47$ \\
\hline Light drinkers & 1.73 & $1.16-2.57$ & 1.34 & $1.04-1.71$ \\
\hline Moderate drinkers (ref.) & 1.00 & & 1.00 & \\
\hline Heavy drinkers & 1.69 & $1.05-2.74$ & 1.54 & $1.01-2.36$ \\
\hline \multicolumn{5}{|l|}{ HED } \\
\hline Abstainers & 1.66 & $0.89-3.13$ & 1.93 & $1.42-2.62$ \\
\hline Drinkers with no HED (ref.) & 1.00 & & 1.00 & \\
\hline HED 1-6 times/year & 0.80 & $0.54-1.16$ & 0.91 & $0.68-1.23$ \\
\hline HED $\leq 3$ times/month & 1.38 & $0.80-2.38$ & 1.02 & $0.70-1.48$ \\
\hline HED > once a week & 2.14 & $1.27-3.58$ & 1.29 & $0.81-2.06$ \\
\hline \multicolumn{5}{|l|}{ Daily smoking } \\
\hline Never daily smoker (ref.) & 1.00 & & 1.00 & \\
\hline Former daily smoker & 1.21 & $0.87-1.68$ & 1.18 & $0.91-1.52$ \\
\hline Daily smoker & 2.29 & $1.25-4.19$ & 1.66 & $1.27-2.16$ \\
\hline \multicolumn{5}{|l|}{ BMI } \\
\hline Underweight, $<18.49$ & 0.55 & $0.09-3.36$ & 1.15 & $0.64-2.05$ \\
\hline Normal, 18.5-24.99 (ref.) & 1.00 & & 1.00 & \\
\hline Overweight, 25-29.99 & 1.14 & $0.76-1.73$ & 1.18 & $0.92-1.52$ \\
\hline Obese, $>30$ & 1.53 & $1.01-2.34$ & 1.47 & $1.08-2.02$ \\
\hline \multicolumn{5}{|l|}{ Physical activity in leisure time } \\
\hline Frequently active (ref.) & 1.00 & & 1.00 & \\
\hline Moderately active & 1.58 & $1.10-2.27$ & 1.26 & $1.01-1.57$ \\
\hline Inactive & 3.22 & $1.75-5.95$ & 1.49 & $1.11-2.02$ \\
\hline \multicolumn{5}{|l|}{ Physical working cond. } \\
\hline Sedentary (ref.) & 1.00 & & 1.00 & \\
\hline Light & 1.61 & $1.03-2.51$ & 1.44 & $1.10-1.88$ \\
\hline Moderate & 2.31 & $1.53-3.48$ & 1.86 & $1.44-2.41$ \\
\hline Heavy & 4.95 & $2.77-8.87$ & 2.89 & $1.97-4.24$ \\
\hline \multicolumn{5}{|l|}{ Job strain } \\
\hline Low strain (ref.) & 1.00 & & 1.00 & \\
\hline Active & 1.11 & $0.75-1.65$ & 1.27 & $0.96-1.66$ \\
\hline Passive & 2.15 & $1.25-3.71$ & 1.34 & $0.85-2.10$ \\
\hline High strain & 2.09 & $1.16-3.79$ & 1.84 & $1.38-2.46$ \\
\hline
\end{tabular}

HED, heavy episodic drinking; BMI, body mass index.

The Contribution of Alcohol Use, Other Lifestyle

Factors and Working Conditions to SEP Differences in Sickness Absence

The results revealed a social gradient in sickness absence for both outcomes (Tables 5, 6). The largest differences were found for long-term sickness absence. Here, manual workers had approximately 4 times higher rates of sickness absence compared to higher nonmanual employees among men, and $>2$ times higher among women. The corresponding SEP differences in self-reported sickness absence were somewhat lower, with RRs of 1.73 (1.54-1.94) for men and 1.44 (1.291.59) for women.
Adjustment for alcohol use (model 2) attenuated the SEP differences in long-term sickness absence by $20 \%$ among men and $14 \%$ among women. For short-term sickness absence, the contribution of alcohol use was somewhat smaller, with attenuations of $11 \%$ among women and $6 \%$ among men. Including alcohol use in combination with the other lifestyle factors (model 3) resulted in larger attenuations of the SEP differences: approximately $30 \%$ for both outcomes among women and for long-term sickness absence among men, and 20\% for short-term sickness absence among men.

The largest attenuations of the SEP differences in sickness absence were obtained after adjustment for 
Table 5. The contribution of alcohol use, other lifestyle behaviours and working conditions to SEP differences in spells of short-term sickness absence. All models, adjusted for age and country of birth

\begin{tabular}{|c|c|c|c|c|c|c|}
\hline \multirow[t]{2}{*}{ Model } & \multicolumn{3}{|l|}{ Men } & \multicolumn{3}{|c|}{ Women } \\
\hline & $\mathrm{RR}^{\mathrm{a}}$ & $95 \%$ CI & $\mathrm{ATT}^{\mathrm{b}}$ & $\mathrm{RR}^{\mathrm{a}}$ & $95 \%$ CI & $\mathrm{ATT}^{\mathrm{b}}$ \\
\hline 1. Crude & 1.73 & $1.54-1.94$ & & 1.44 & $1.29-1.59$ & \\
\hline 2. Alcohol use ${ }^{c}$ & 1.68 & $1.50-1.89$ & 6 & 1.39 & $1.25-1.54$ & 11 \\
\hline 3. Alcohol use ${ }^{c}+$ lifestyle factors ${ }^{d}$ & 1.58 & $1.40-1.79$ & 20 & 1.29 & $1.15-1.43$ & 35 \\
\hline 4. Physical working conditions & 1.69 & $1.45-1.97$ & 5 & 1.31 & $1.15-1.49$ & 30 \\
\hline 5. Psychosocial working conditions & 1.52 & $1.34-1.72$ & 29 & 1.41 & $1.27-1.57$ & 6 \\
\hline 6. Fully adjusted & 1.37 & $1.17-1.60$ & 49 & 1.20 & $1.05-1.37$ & 55 \\
\hline
\end{tabular}

${ }^{a}$ RRs of manual workers compared to higher non-manual employees.

${ }^{\mathrm{b}}$ Percentage attenuation in the crude RRs after adjustment for the explanatory variables.

${ }^{c}$ Volume of consumption and frequency of HED.

${ }^{\mathrm{d}}$ Daily smoking, BMI, physical activity.

$\mathrm{SEP}$, socioeconomic position; RR, rate ratios; HED, heavy episodic drinking; BMI, body mass index.

Table 6. The contribution of alcohol use, other lifestyle behaviours and working conditions to SEP differences in long-term sickness absence. All models, adjusted for age and country of birth

\begin{tabular}{|c|c|c|c|c|c|c|}
\hline \multirow[t]{2}{*}{ Model } & \multicolumn{3}{|l|}{ Men } & \multicolumn{3}{|c|}{ Women } \\
\hline & $\mathrm{RR}^{\mathrm{a}}$ & $95 \% \mathrm{CI}$ & $\mathrm{ATT}^{\mathrm{b}}$ & $\mathrm{RR}^{\mathrm{a}}$ & $95 \% \mathrm{CI}$ & $\mathrm{ATT}^{\mathrm{b}}$ \\
\hline 1. Crude & 3.98 & $2.30-6.87$ & & 2.41 & $1.75-3.34$ & \\
\hline 2. Alcohol use $\mathrm{e}^{\mathrm{c}}$ & 3.39 & $2.10-5.47$ & 20 & 2.22 & $1.59-3.10$ & 14 \\
\hline 3. Alcohol use ${ }^{\mathrm{c}}+$ lifestyle factors ${ }^{\mathrm{d}}$ & 3.06 & $1.94-4.82$ & 31 & 2.03 & $1.44-2.87$ & 27 \\
\hline 4. Physical working conditions & 2.40 & $1.37-4.21$ & 53 & 1.66 & $1.13-2.44$ & 53 \\
\hline 5. Psychosocial working conditions & 3.99 & $2.35-6.75$ & 0 & 2.31 & $1.64-3.25$ & 7 \\
\hline 6. Fully adjusted & 1.78 & $1.06-2.98$ & 74 & 1.40 & $0.93-2.10$ & 72 \\
\hline
\end{tabular}

${ }^{\text {a }}$ RRs of manual workers compared to higher non-manual employees.

b Percentage attenuation in the crude RRs after adjustment for the explanatory variables.

${ }^{c}$ Volume of consumption and frequency of HED.

${ }^{\mathrm{d}}$ Daily smoking, BMI, physical activity.

SEP, socioeconomic position; RR, rate ratios; HED, heavy episodic drinking; BMI, body mass index.

physical working conditions (model 4). However, for men, this factor had a considerably larger statistical effect on the SEP differences in long-term compared to short-term sickness absence. The attenuations of longterm sickness absence amounted to just over $50 \%$ for both sexes. The corresponding attenuations for self-reported sickness were somewhat lower, $30 \%$, for women, and only marginal at around 5\% for men. Conversely, adjusting for psychosocial working conditions (model 5) led to larger attenuations in short-term (29\%) compared to long-term (0\%) sickness absence for men and to smaller attenuations in both outcomes $(6-7 \%)$ for women.

Socioeconomic Differences in Sickness Absence
In the fully adjusted model, where all explanatory variables were included concurrently, the largest attenuation, just over $70 \%$, was found for long-term sickness absence, whereas the reduction was somewhat smaller, around $50 \%$, for short-term sickness absence.

\section{Sensitivity Analyses}

In additional analyses, we estimated the separate contribution of volume of consumption and frequency of HED (results not shown). The findings showed that volume of consumption accounted for a considerably smaller proportion of the social differences in long-term sickness absence among men (3\%) than the measure of HED 
(17\%). However, among women, and in the analyses of short-term sickness absence, the attenuations attributed to each aspect of alcohol use measure were similar.

Next, we included having $>100$ days of register-based sickness absence during follow-up as outcome (results not shown). The crude RRs for SEP were somewhat larger in these analyses, $5.34(2.49-11.45)$ for men and 2.81 (1.73-4.56) for women. Moreover, compared to our main analyses, adjusting for alcohol use resulted in a larger attenuation, 18\%, among women. For the remaining models, the estimates and attenuations were basically similar to those in the main models.

Finally, to assess whether the effect of alcohol use could be attributed to the increased risk for sickness absence among abstainers, we fitted models that excluded this group. Adjusting for alcohol use in these analyses resulted in attenuations that were similar to those in the main models for men. However, for women, the attenuation for both long-term and short-term sickness absence became only marginal, at approximately $5 \%$.

\section{Discussion/Conclusion}

Our study is the first to estimate the individual contribution of alcohol use to SEP differences in short-term and long-term sickness absence, taking into account the contribution of both levels and patterns of drinking.

Overall, our findings revealed that the role of alcohol use for the social gradient in sickness-absence varies across the outcomes and between the sexes. The largest contribution was found for long-term sickness absence, and especially among men, where alcohol use statistically explained about a fifth of the differences in sickness absence between manual workers and higher non-manual employees. Conversely, alcohol use only explained a marginal proportion, $6 \%$, of the socioeconomic differences in short-term sickness absence among men. In women, alcohol use also explained a larger proportion of long-term than of short-term sickness absence, but the difference between the outcomes was more modest, with attenuations of 14 and $11 \%$ respectively.

The finding that alcohol use accounts for a larger proportion of the social gradient in long-term sickness absence most likely reflects that the social gradient in alcohol-related harm also tends to be steeper for more severe consequences, for example, alcohol-related morbidity, which in turn are more closely related to long-term than short-term sickness absence. In fact, for men, the proportion of the social gradient in long-term sickness absence that was explained by alcohol use is similar to what we have previously found in relation to alcohol-related disorders [27]. In line with previous research on the role of alcohol use for the social gradient in health outcomes such as alcohol-related morbidity and total mortality, we also found that frequency of HED, rather than volume of consumption, contributes to the gradient in long-term sickness among men $[26,27]$. This may partly be attributed to the social gradient being steeper for HED, and that HED had a stronger effect on long-term sickness absence than volume of consumption in our sample. On the other hand, HED explained less of the SEP differences in long-term sickness absence among women. This might be due to the HED measure having a high threshold, corresponding to, for example, at least 2 bottles of wine per occasion, resulting in a low prevalence among women (only $2 \%$ reported HED at least once a week, compared to $8 \%$ among men). Hence, owing to power issues and/or failure to identify women whose behaviour included HED at lower levels, it is possible that the contribution of alcohol use to the social gradient in sickness absence among women is somewhat underestimated in the present study. Still, taken together, our findings underline the importance of including valid measures of both levels and patterns of drinking to avoid underestimating the role of alcohol use for social disparities in sickness absence.

It should also be mentioned that we, in line with previous studies, found a U-shaped risk-function between alcohol use and sickness absence, with increased risk among abstainers and heavy drinkers [17, 20,33]. In relation to this, our sensitivity analyses revealed that alcohol use accounted for considerably less of the SEP-differences in sickness absence among women, after we excluded abstainers from the sample. Still, it is not evident how the effect of abstainers should be interpreted in this context. On the one hand, the increased risk for sickness absence among abstainers may indicate a protective effect of moderate consumption, in which case the effect of alcohol use on the social gradient in sickness absence among women largely may be attributed to abstainers being overrepresented in lower SEP groups. On the other hand, the increased risk among abstainers may also be attributed to sick quitter bias, that is, that individuals tend to abstain from alcohol due to former drinking problems and/or other health problems $[16,33]$. Hence, to obtain a more valid assessment of what degree the increased risk for sickness absence in this group is due to actual abstention, or to former alcohol problems, the group of abstainers needs to be stratified into former drinkers and lifetime 
abstainers. Unfortunately, we did not have this information in the present study.

In relation to previous research, our estimated contributions of alcohol use to SEP differences in sickness absence are considerably larger than what previously have been reported by a Finnish study of medically certified sickness absence ( $>4$ days) among municipal employees [9]. The differences in results may partly be explained by that the Finnish study only controlled for a crude measure of weekly drinking and failed to take into account the effect of HED. Still, our finding that alcohol use in combination with other lifestyle factors (smoking, physical activity and BMI) account for 20-35\%, of the SEP-differences in both outcomes are in line with the findings by Laaksonen et al. [9], but somewhat larger than what Christensen et al. [8] found for long-term sickness absence (exceeding 8 consecutive weeks) in a Danish population sample.

In line with previous research, we also found physical, rather than psychosocial working conditions, to be the key explanatory variable for SEP differences in long-term sickness absence $[8-10,12]$ - with more than half of the gradient attributed to this factor among men and women. This finding may largely be attributed to the unequal exposure to heavy working conditions across the occupational classes, and probably reflects that physical impairment may cause more long-term inability to carry out work tasks among manual workers compared to higher occupational classes $[9,10]$. However, what our study adds to previous findings is that physical working conditions seem to be of little importance for the SEP differences in self-reported short-term spells ( $<14$ days) of sickness absence among men. Conversely, for this less severe outcome, psychosocial working conditions appear to have a greater impact among men.

Finally, there are indications from previous research that working conditions may explain a part of the relationship between alcohol use and sickness absence [34, 35]. It is thus possible that low SEP employees tend to use alcohol as a coping strategy for adverse working conditions, resulting in both problematic drinking and related sickness absence. In this case, the alcohol effect on the social gradient in sickness absence would be partly spurious. To address this issue, we conducted 2 additional analyses (not shown). First, we adjusted the bivariate associations between alcohol use and sickness absence for working conditions, which did not materially affect the estimates. Second, to test whether alcohol use had an effect on the SEP differences sickness absence, over and above working conditions, we added alcohol use to the

Socioeconomic Differences in Sickness

Absence models including working conditions. In all cases, the SEP differences were further attenuated, indicating that alcohol use has an effect on the social gradient in sickness absence, independent of working conditions.

Strengths of this study included a large representative sample, information on both self-reported and registerbased sickness absence as well as a prospective study design. Moreover, the calibrated weights used for the SPHC data account for socioeconomic differences and, therefore, balance possible under-representation of low SEP groups. Some limitations of the study should also be noted. First, there is most probably an under-representation of heavy and problem drinkers in the sample, implying that the effect of alcohol on sickness absence is somewhat underestimated. Second, although our finding that SEP differences are smaller for short-term than long-term sickness absence is in line with previous studies [36, 37], the results for short-term sickness absence should be regarded with more caution. Considering that short-term sickness absence was measured by self-reports and long-term absence by registry data, there is a larger risk of underestimating the actual levels of shortterm sickness absence as well as the SEP differences for this outcome. Third, the cross-sectional study design for short-term sickness absence implies poorer prospects of establishing causality. For instance, it is possible that the occurrence of short-term sickness absence may have had an effect on how the respondents report on their psychosocial work environment. Finally, alcohol use and the other explanatory factors were only measured at baseline. Recent studies indicate that accounting for changes in health behaviours over time tends to result in larger estimates of their effects on socioeconomic differences in health $[38,39]$.

\section{Conclusion}

Alcohol use explains about a fifth of the SEP differences in long-term sickness absence among men. The explanatory effect of alcohol is smaller among women (where it also partly is attributable to abstainers being overrepresented in the lowest SEP group) and for shortterm sickness absence. However, alcohol use - in combination with other lifestyle factors, including smoking, physical activity and BMI - accounts for a more substantial part of the relationship for both outcomes. Moreover, our findings support the notion that physical working conditions constitute the key explanatory variable for SEP differences in long-term sickness absence. Finally, 
our study also adds that psychosocial working conditions have a greater impact on the social disparities in shortterm sickness absence among men.

\section{Statement of Ethics}

Respondents to the SPHC baseline survey gave informed consent for register linkage. Ethical approval for the present study was obtained from the Regional Ethical Review Board in Stockholm: Dnr 2016/320-31/5.

\section{Disclosure Statement}

The authors have no conflicts of interest to declare.

\section{Funding Sources}

This study was funded by Forte, Swedish Research Council for Health, Working Life and Welfare (Swedish: Forskningsrådet för hälsa, arbetsliv och välfärd) Dnr: 2014-02040.

\section{References}

1 Marmot M, Feeney A, Shipley M, North F, Syme SL. Sickness absence as a measure of health status and functioning: from the UK Whitehall II study. J Epidemiol Community Health. 1995 Apr;49(2):124-30.

2 Alexanderson K, Norlund A. Chapter 1. Aim, background, key concepts, regulations, and current statistics. Scand J Public Health. 2004 Oct 32;(63_suppl):12-30.

3 Piha K. Socio-economic determinants of sickness absence. Publications of Public Health. Department of Public Health. Helsinki: University of Helsinki; 2013.

4 Kivimäki M, Head J, Ferrie JE, Shipley MJ, Vahtera J, Marmot MG. Sickness absence as a global measure of health: evidence from mortality in the Whitehall II prospective cohort study. BMJ. 2003 Aug;327(7411):364.

5 Kivimäki M, Forma P, Wikström J, Halmeenmäki T, Pentti J, Elovainio M, et al. Sickness absence as a risk marker of future disability pension: the 10-town study. J Epidemiol Community Health. 2004 Aug;58(8):710-1.

6 Vahtera J, Pentti J, Kivimäki M. Sickness absence as a predictor of mortality among male and female employees. J Epidemiol Community Health. 2004 Apr;58(4):321-6.

7 Allebeck P, Mastekaasa A. Risk factors for sick leave - general studies. Scand J Public Health. 2004 Oct 32;(63_suppl):49-108.

8 Christensen KB, Labriola M, Lund T, Kivimäki M. Explaining the social gradient in longterm sickness absence: a prospective study of Danish employees. J Epidemiol Community Health. 2008 Feb;62(2):181-3.

9 Laaksonen M, Piha K, Rahkonen O, Martikainen P, Lahelma E. Explaining occupational class differences in sickness absence: results from middle-aged municipal employees. Epidemiol Community Health. 2010 Sep; 64(9):802-7.

10 Löve J, Hensing G, Holmgren K, Torén K. Explaining the social gradient in sickness absence: a study of a general working population in Sweden. BMC Public Health. 2013 Jun; 13(1):545.

11 Robroek SJ, van Lenthe FJ, Burdorf A. The role of lifestyle, health, and work in educa- tional inequalities in sick leave and productivity loss at work. Int Arch Occup Environ Health. 2013 Aug;86(6):619-27.

12 Kaikkonen R, Härkänen T, Rahkonen O, Gould R, Koskinen S. Explaining educational differences in sickness absence: a populationbased follow-up study. Scand J Work Environ Health. 2015 Jul;41(4):338-46.

13 Rehm J, Room R, Monterio M, Gmel G, Graham K. Alcohol. In: Ezzati M, Lopez AD, Rodgers A, Murray CJ, editors. Comparative Quantification of Health Risks. Global and Regional Burden of Disease Attributable to Selected Major Risk Factors. Volume 1. Geneva: World Health Organisation; 2004. pp. 959-1108.

14 Norström T. Per capita alcohol consumption and sickness absence. Addiction. 2006 Oct; 101(10):1421-7.

15 Babor TC, Casswell R, Edwards S, Giesbrecht G, Graham N, Grube K, et al. Room R, Rossow I, Alcohol: No Ordinary Commodity: Research and Public Policy. 2nd ed. Oxford: Oxford University Press; 2010.

16 Schou L, Moan IS. Alcohol use-sickness absence association and the moderating role of gender and socioeconomic status: A literature review. Drug Alcohol Rev. 2016 Mar;35(2): 158-69.

17 Upmark M, Möller J, Romelsjö A. Longitudinal, population-based study of self reported alcohol habits, high levels of sickness absence, and disability pensions. J Epidemiol Community Health. 1999 Apr;53(4):223-9.

18 Ervasti J, Kivimäki M, Head J, Goldberg M, Airagnes G, Pentti J, et al. Sociodemographic differences between alcohol use and sickness absence: pooled analysis of four cohort studies. Alcohol Alcohol. 2018 Jan;53(1):95-103.

19 Miquel L, Manthey J, Rehm J, Vela E, Bustins M, Segura L, et al. Risky alcohol use: the impact on health service use. Eur Addict Res. 2018;24(5):234-44

20 Jørgensen MB, Thygesen LC, Becker U, Tolstrup JS. Alcohol consumption and risk of unemployment, sickness absence and disability pension in Denmark: a prospective cohort study. Addiction. 2017 Oct;112(10):1754-64.
21 Hensing G, Petersson E, Spak F, Östlund G. Alkoholkonsumtion, alkoholproblem och sjukfrånvaro - vilka är sambanden? en systematisk litteraturöversikt. (Alcohol consumption, alcohol problems and sickness absence - what are the associations? A systematic literature review) SOU 2010:47. Stockholm: Fritze; 2010.

22 Baumberg B. The global economic burden of alcohol: a review and some suggestions. Drug Alcohol Rev. 2006 Nov;25(6):537-51.

23 Schmidt L, Mäkelä P, Rehm J, Room R. Alcohol: Equity and Social Determinants. Geneva: World Health Organization; 2009.

24 Probst C, Roerecke M, Behrendt S, Rehm J. Socioeconomic differences in alcohol-attributable mortality compared with all-cause mortality: a systematic review and meta-analysis. Int J Epidemiol. 2014 Aug;43(4):1314-27.

25 Rehm J, Probst C. Decreases of life expectancy despite decreases in non-communicable disease mortality: the role of substance use and socioeconomic status. Eur Addict Res. 2018; 24(2):53-9.

26 Sydén L, Landberg J. The contribution of alcohol use and other lifestyle factors to socioeconomic differences in all-cause mortality in a Swedish cohort. Drug Alcohol Rev. 2017 Sep;36(5):691-700.

27 Sydén L, Sidorchuk A, Mäkelä P, Landberg J. The contribution of alcohol use and other behavioural, material and social factors to socioeconomic differences in alcohol-related disorders in a Swedish cohort. Addiction. 2017 Nov;112(11):1920-30.

28 Svensson AC, Fredlund P, Laflamme L, Hallqvist J, Alfredsson L, Ekbom A, et al. Cohort profile: the Stockholm public health cohort. Int J Epidemiol. 2013 Oct;42(5):1263-72.

29 Statistics Sweden. Socioekonomisk Indelning (SEI) [Swedish Socio-Economic Classification]. Reports on statistical co-ordination. Stockholm: Statistics Sweden; 1983.

30 Smyth A, Teo KK, Rangarajan S, O'Donnell M, Zhang X, Rana P, et al.; PURE Investigators. Alcohol consumption and cardiovascular disease, cancer, injury, admission to hospital, and mortality: a prospective cohort study. Lancet. 2015 Nov;386(10007):1945-54. 
31 Karasek R, Theorell T. Healthy work: Stress, productivity, and the reconstruction of working life. NewYork: Basic Books; 1990.

32 de Lange $\mathrm{AH}$, Taris TW, Kompier MA, Houtman IL, Bongers PM. "The very best of the millennium": longitudinal research and the demand-control-(support) model. J Occup Health Psychol. 2003 Oct;8(4):282305.

33 Vahtera J, Poikolainen K, Kivimäki $M$, Ala-Mursula L, Pentti J. Alcohol intake and sickness absence: a curvilinear relation. Am J Epidemiol. 2002 Nov;156(10): 969-76.
34 Vasse RM, Nijhuis FJ, Kok G. Associations between work stress, alcohol consumption and sickness absence. Addiction. 1998 Feb; 93(2):231-41.

35 Salonsalmi A, Laaksonen M, Lahelma E, Rahkonen O. Drinking habits and sickness absence: the contribution of working conditions. Scand J Public Health. 2009 Nov;37(8): 846-54.

36 Kristensen TR, Jensen SM, Kreiner S, Mikkelsen S. Socioeconomic status and duration and pattern of sickness absence. A 1-year follow-up study of 2331 hospital employees. BMC Public Health. 2010 Oct;10(1):643.
37 Vahtera J, Virtanen P, Kivimäki M, Pentti J. Workplace as an origin of health inequalities. J Epidemiol Community Health. 1999 Jul; 53(7):399-407.

38 Stringhini S, Sabia S, Shipley M, Brunner E, Nabi H, Kivimaki M, et al. Association of socioeconomic position with health behaviors and mortality. JAMA. 2010 Mar;303(12): 1159-66.

39 Nandi A, Glymour MM, Subramanian SV. Association among socioeconomic status, health behaviors, and all-cause mortality in the United States. Epidemiology. 2014 Mar; 25(2):170-7. 